\title{
LA HERMENÉUTICA FILOSÓFICA Y LA "CORRECTA" INTERPRETACIÓN JURÍDICA
}

\author{
Philosophical Hermeneutics and the "Correct" Legal Interpretation \\ J. Merced RIZO CARMONA*
}

Sumario:

I. Introducción II. Carl Schmitt y la decisión judicial "correcta” III. Theodor Viehwegy la tópica jurídica IV. Chaïm Perelman y la nueva retórica $V$. Aportaciones de la hermenéutica filosófica de Gadamer a la hermenéutica jurídica VI. Reflexiones finales

Resumen: En este artículo se trata de argumentar a favor de la hermenéutica filosófica de Hans-Georg Gadamer como un apoyo o complementación de la interpretación jurídica. Principalmente, se considera que tanto la parte lógica de los enunciados jurídicos (la validez), el aspecto material (la verdad y los contenidos), así como las posibles retóricas axiológicas que puedan generar hipótesis semánticas, son fundamentales para la creación de una "correcta" interpretación jurídica; es decir, la tesis que sirve como punto de partida es que toda interpretación debe ser el producto de una actividad básicamente racional y contextual. Para el análisis metodológico se hizo la comparación de la propuesta de Gadamer con formas de interpretación eminentemente jurídicas de pensadores como Carl Schmitt, Theodor Viehweg y Chaïm Perelman.

Palabras clave: Hermenéutica, Interpretación, Decisionismo, Tópica, Retórica

\begin{abstract}
In this article we have tried to argue in favor of Hans-Georg Gadamer's Philosophical Hermeneutics as a support or completion of its legal interpretation. Mainly, it is considered that both the logical part of the legal statements (validity), the material aspect (the truth and content) as well as the possible axiological rhetoric that can generate semantic hypothesis are fundamental to the creation of a "correct" legal interpretation; i.e., the thesis that serves as a starting point is that any interpretation must be the product of a basically rational and contextual activity. For the methodological analysis, Gadamer's proposal was compared to forms of eminently legal interpretation of such thinkers as Carl Schmitt, Theodor Viehweg and Chaïm Perelman.
\end{abstract}

Keywords: Hermeneutics, Interpretation, Decisionism, Topical, Rhetoric

\footnotetext{
* Profesor de tiempo completo en la Universidad de Guanajuato.
} 


\section{Introducción}

El pensamiento filosófico de la antigua Grecia estuvo vinculado a la reflexión sobre la política, las formas de gobierno y la justicia. En la actualidad, en el campo del Derecho, las teorías hermenéuticas contemporáneas pueden abonar, particularmente, a la teoría y la práctica de la interpretación jurídica. Por esta razón, se considera de suma relevancia que las investigaciones de la ciencia jurídica, de forma transversal, se auxilien de los marcos filosóficos en lo que refiere a la argumentación, la interpretación y comprensión de las leyes.

La hermenéutica filosófica, en la teoría de Hans-Georg Gadamer, implica tres momentos de un proceso unificado de toda experiencia, como la jurídica: a) La comprensión como conocimiento de sí mismo no es un ensimismamiento, sino la comprensión del otro; un encuentro vital de humanos entre humanos. b) Con la interpretación, el sujeto de un proceso jurídico se acerca al texto a interpretar desde su horizonte. c) Con la aplicación, el sujeto al comprender e interpretar pone en juego sus presupuestos particulares, experiencias o historicidad, y al hacerlo el sujeto afecta su manera de ser: se autocomprende.

Desde la perspectiva de la hermenéutica filosófica, en tanto que hace referencia a la ontología de la interpretación y la comprensión del ser humano, se trata de reflexionar acerca de si es posible que el jurista, en la actuación judicial, pueda encontrar un apoyo favorable en dicha hermenéutica filosófica, pues el Derecho se ha constituido como una disciplina mediada por la interpretación. Para responder la interrogante se intentará argumentar cómo, desde el espacio lingüístico-pragmático, Gadamer (la hermenéutica), Schmitt (el decisionismo), Viehweg (la tópica) y, con una fuerte consciencia filosófica, Perelman (la nueva retórica), reivindican el antiguo concepto de la tópica (sustentada en la dialéctica y la retórica) como reflexión de la peculiaridad del conocimiento y la praxis jurídica; estos autores destacan, con distintos matices, los métodos del discurso persuasivo y retórico contra la forma de demostración lógica del positivismo científico ${ }^{1}$.

Al respecto, la comparación de la propuesta de Gadamer de los pensadores del derecho que se refirieron tiene como objetivo ver cómo aquél, desde el ámbito propio de la filosofía, podría, con sus principales conceptos de la hermenéutica filosófica, abonar al quehacer de la jurisprudencia ${ }^{2}$. Se verá, por ejemplo, cómo Gadamer coincide en una parte con el decisionismo de Schmitt, cuando éste precisa que la decisión judicial va más allá de un sistema-deductivo de normas; también se tratará de explicitar las diferencias, sobre todo políticas, de Gadamer con el antiliberalismo, el nazismo ${ }^{3}$ y el subjetivismo de Schmitt.

\footnotetext{
' Gadamer, Hans-Georg (2006a), Verdad y método II, trad. Manuel Olasagasti, 7a. ed., España, Sígueme, pp. 368-369.

2 Riccardo Guastini, acerca de los objetos de la interpretación, señala que se pueden interpretar hechos (subsumirlos en una norma, calificarlos o bien aplicarles una consecuencia jurídica según lo prevea la norma), también se pueden interpretar textos (atribuirles sentido o significado); la interpretación jurídica es un tipo de interpretación de textos (leyes, reglamentos, sentencias, etc.). GuAstini, Riccardo (2012), Estudios sobre la interpretación jurídica, México, Porrúa/UNAM, pp. 1-3.

3 Aunque el interés para este trabajo es meramente jurídico, es sabido de los intereses y las filiaciones de Carl Schmitt con el nazismo, Antonio Gnoli refiere que Schmitt es un reconocido jurista, pero comprometido con el régimen nazi. GNoli, Antonio (1995), "Entre razón y pasión. Bobbio recuerda a Schmitt", en: Schmitt, Carl (2008), El Leviatán en la doctrina del Estado de Thomas Hobbes, México, Distribuciones Fontamara, p. 43. Por su parte, Carlos Bravo señala que la reacción de Schmitt ante el ascenso de los nazis al poder fue de aprehensión (pues consideraba a los nazis como un grupo de vándalos extremistas y fanáticos) y de esperanza (en el nazismo como una forma política de terminar con la inestabilidad). BRAVO
} 
En última instancia y en palabras de Friedrich Karl von Savigny ${ }^{4}$, la tarea de la interpretación tiene una triple composición: la parte lógica que presenta tanto el origen y la relación de las partes entre sí de la ley (las premisas con sus términos y la conclusión); la parte gramatical que ayuda a la estructura lógica (sintaxis, semántica y pragmática); y, la parte histórica, ya que toda ley está dada en un contexto (tiempo y espacio) determinado, más precisamente, se refiere a un pueblo o a una tradición específica. De ahí que la interpretación es reconstrucción del pensamiento (claro u oscuro, es igual) expresado en la ley en cuanto sea conocible en la ley5.

En este sentido, entender-interpretar una ley o norma comprendería captar racionalmente las relaciones que la norma mantiene con otros aspectos o enunciados -políticos, valorativos, históricos, etcétera- del discurso hermenéutico jurídico, pues la interpretación jurídica es algo más que una cuestión lingüística y no puede verse reducida a asunto de palabras 6 .

Gadamer considera que la influencia de la hermenéutica en el plano de la jurisprudencia ha adquirido varios impulsos a modo de complemento de la dogmática jurídica. Sobre todo porque aquélla procura un acercamiento al humanismo jurídico al recuperar categorías como la dialéctica y la retórica.

\section{Carl Schmitt y la decisión judicial "correcta"}

Sin duda, tanto el pensamiento jurídico que lo caracterizó como las decisiones políticas que tomó Carl Schmitt lo vuelven un pensador difícil de abordar. Debido a su visión anti-moderna y anti-liberal sería muy complicado estar de acuerdo con él. Sobre todo, a inicios de este siglo, en el que se trata de tomar distancia de cualquier vestigio de los totalitarismos que caracterizaron el siglo xx. No obstante, su obra se ha vuelto un clásico, en el sentido de que todavía tendría algo que decir hoy ${ }^{7}$ y no precisamente porque se esté de acuerdo con sus tesis.

La perspectiva del mundo y de la sociedad que tenía Schmitt lo llevaron a constituir una obra sistemática y congruente en sí misma: su pensamiento político se entrelaza con el jurídico, es decir, el poder tiene una estrecha relación con el Derecho ${ }^{8}$. Asimismo, para Schmitt, de la esencia de la política dependerá todo lo demás; tal esencia refiere a que todos los conceptos centrales de la moderna teoría del Estado son conceptos teológicos

REgidor, Carlos, et. al., (2013), ¿Por qué leer a Schmitt hoy?, México, Distribuciones Fontamara, p. 19.

4 SAvigny, Friedrcih Karl von (2004), Metodología jurídica, Buenos Aires, Argentina, Valletta Ediciones, p. 25.

5 Ibidem, p. 26.

6 Vernengo, Roberto J. (1994), La interpretación literal de la ley, Buenos Aires, Argentina, Abeledo-Perrot p. 20.

7 Carlos Bravo Regidor se pregunta: ¿Vale la pena leerlo hoy [a Schmitt]? Sí, porque a pesar de que su teología política se ubica en las antípodas de una visión estratégica del poder, de una comprensión sociológica del derecho, de un conocimiento histórico sobre la formación de un orden constitucional, la inquietud que le dio origen es todavía muy relevante. ¿Cómo se instaura y se sostiene una legalidad? La respuesta que ofreció, la soberanía, fue un paso en falso. No una solución, sino una huida. BRAVo REGIDOR, Carlos, et. al., (2013), op. cit., nota 3, p. 30.

8 Córdova Vianello, Lorenzo (2009), "El amigo-enemigo como expresión de la antidemocraticidad del pensamiento de Carl Schmitt”, en: Ibidem, pp. 31 y 32. 
secularizados... el estado de excepción tiene en la jurisprudencia análoga significación que el milagro en la teología . A continuación, se tratará de reflexionar la forma en cómo Schmitt infiere el aspecto de la correcta decisión jurídica.

Para Schmitt ${ }^{10}$, la legalidad o los complejos sistemas de normas pre-jurídicos, como la lógica formal (que se encarga de las inferencias válidas en virtud únicamente de su forma), carecen de valor como único criterio de corrección de una decisión judicial, pues dichos sistemas ignoran elementos importantes de la vida jurídica. De igual manera, dirá Schmitt: En toda decisión jurídica concreta hay un margen de indiferencia hacia el contenido, porque la conclusión jurídica no se puede deducir completamente de sus premisas ${ }^{11}$. Schmitt tiene en mente el origen causal o psicológico de la decisión, aunque precisa, específicamente, que hay que considerar la estimación cierta del valor jurídico. Por esta razón, la tarea del teórico del derecho es encontrar un criterio autóctono para la praxis judicial.

Así, el paradigma decisionista que estableció Schmitt refiere que todo tipo de orden descansa sobre una decisión. Igualmente, por ejemplo, en la relación entre el poder y el derecho, concibe todo derecho como decisión y toda decisión como acto de poder. Pues también el orden jurídico descansa en una decisión y no en una norma o sistema legal ${ }^{12}$. Lo anterior no significa para Schmitt, igual tampoco para Gadamer, que quede suspendida toda regla objetiva y que entonces todo termine dependiendo de la subjetividad, pues en ningún momento puede el juez ejercer una absoluta discrecionalidad ${ }^{13}$ ya que la fundamentación forma parte de la decisión.

No obstante, tanto para Schmitt como para Gadamer, cualquier deducción que se haga a partir de una idea de derecho que pretenda una validez supra temporal (o ahistórica) corre el riesgo de negar los contenidos jurídicos. Lo que se debe enfatizar es que para Schmitt la noción de ley no refiere a un mero mecanismo legal, sino que le precede el carácter legitimante del poder del soberano ${ }^{14}$, que es quien decide sobre el estado de excepción, pues la soberanía es poder supremo y originario de mandar ${ }^{15}$; por ello el derecho no puede ser limitación, obstáculo o superación del poder ${ }^{16}$.

De lo que se trata, según Schmitt, es que la praxis judicial ponga en sintonía los precedentes normativos con otro tipo de explicaciones que intervienen en la decisión judicial, tales como la colegialidad (la autoridad de otros jueces) o la apelación (la soberanía de los distintos órganos judiciales), pues el criterio de la corrección de una

\footnotetext{
${ }_{9}$ Schmitt, Carl (2009), Teología política, España, Trotta, p. 37.

${ }^{10}$ Sснмітт, Carl (2012), Posiciones ante el derecho, España, Tecnos, pp. 99 y ss.

${ }^{11}$ Sснмітт, Carl (2009), op. cit., nota 9, p. 31.

${ }^{12}$ Ibidem., p. 16.

${ }^{13}$ Sснмітт, Carl (2012), op. cit., nota 10, p. 109.

${ }^{14}$ Ya Nietzsche había visualizado algo con respecto a la autoridad del soberano: Un orden de derecho pensado como algo soberano y general, pensado no como medio en la lucha de complejos de poder, sino como medio contra toda lucha en general, de acuerdo, por ejemplo, con el patrón comunista de Dühring, sería un principio hostil a la vida, un orden destructor y disgregador del hombre, un atentado al porvenir del hombre, un signo de cansancio, un camino tortuoso hacia la nada. NIETZSCHE, Friedrich (2008), La genealogía de la moral. Un escrito polémico, España, Alianza Editorial, pp. 98-99.

${ }^{15}$ Sснмітт, Carl (2009), op. cit., nota 9, p. 13.

${ }^{16}$ Attili, Antonella (1997), "La sombra del Leviatán en el pensamiento de lo político de Carl Schmitt", en: Schmitt, Carl (2008), El Leviatán en la doctrina del Estado de Thomas Hobbes, México, Distribuciones Fontamara, p. 32.
} 
decisión judicial no puede transferirse a procesos sentimentales de los individuos o a sus convicciones subjetivas.

Veremos que esta postura intenta ligar la decisión judicial con esquemas de racionalidad práctica o con algún tipo de determinación axiológica; no obstante, en el caso de Schmitt, los valores deben ser decididos e interpretados por quien detenta el poder. Pues, la realidad del derecho contiene elementos que no son propios de la norma jurídica general positiva cuando de su aplicación se trata, ya que la conclusión jurídica no se puede deducir completamente de sus premisas, por lo que el razonamiento demostrativo no es suficiente, sino que se requiere del pensamiento dialéctico y de la retórica.

En primera instancia, Gadamer estaría de acuerdo en que la decisión judicial correcta no sólo es asunto de la norma, sino también de cierta praxis; no obstante, sería conveniente establecer la diferencia de matices entre Gadamer y Schmitt, al menos en algunos aspectos.

Para Schmitt la fuente de la decisión legal, acerca de lo justo o lo injusto, es la autoridad soberana (visión muy distinta a la que considera la política basada en el ideal de la discusión racional y de una pretendida democracia como señalará Gadamer); por ello formula su conocida frase acerca de que el orden legal se funda en una decisión y no en una norma, más aún: Si en los casos normales cabe reducir al mínimo el elemento autónomo de la decisión, es la norma la que en el caso excepcional se aniquila ${ }^{17}$. Por esta razón la excepción es más determinante que la regla y por ello la tarea del derecho no es la búsqueda de la validez de un sistema jurídico, sino que el derecho sea eficiente en situaciones concretas, particularmente cuando en el Estado surgen situaciones anormales o estados de excepción, en el sentido de que son casos críticos o casos límite, es decir, casos no previstos en el orden jurídico vigente ${ }^{18}$.

El decisionismo de Schmitt surge justamente de estos estados de excepción, de estos estados que perturban la unidad y el orden del esquema racionalista; pues debido a que ninguna norma resulta aplicable a una situación anormal deviene entonces la decisión sobre la excepción: La excepción es más interesante que el caso normal. Lo normal nada prueba; la excepción, todo ${ }^{19}$.

Tampoco para Schmitt (quien tiene en mente la tesis de Hobbes de que la Autoritas, non veritas facit legen / La autoridad, no la verdad, hace la ley) lo más importante es la existencia de una verdad, sino que alguien se halle investido de la autoridad y el poder suficientes para determinar lo que es o significa la verdad, con ello el decisionismo de Schmitt adquiere dimensiones políticas y éticas ${ }^{20}$, en las que explícitamente, en su teoría, el soberano, la autoridad, decide sobre los aspectos legales y morales que garantizan la

\footnotetext{
${ }^{17}$ Sснмiт, C. (2009), op. cit., nota 9, p. 18.

${ }^{18}$ Ibidem, p. 14.

${ }^{19}$ Ibidem, p. 20.

${ }^{20}$ La visión política de Schmitt tiene su raíz en la teoría hobbesiana que, con su Leviatán estatal dotado de un incuestionado poder soberano, que concentra en él toda decisión sobre fe, justicia y mandatos. ATTILI, Antonella (1997), art. cit., nota 16, p. 13. Crea y defiende la unidad política del Estado. Este Estado de derecho, fuente de la justicia y la legalidad, asumido por Hobbes, le ofrece a Schmitt los fundamentos teóricos para un rescate del Estado soberano sin limitación en sus funciones. Así, Hobbes sienta las bases del positivismo jurídico (Ibídem, p. 23), debido al decisionismo afirmado por la fórmula auctoritas y potestas, la cual sostiene que el soberano crea la ley para constituir (crear, modificar, anular) el derecho.
} 
unidad del Estado. Esto conlleva una postura muy cercana a un antiliberalismo político, pues una autoridad pública de carácter supremo no consiente una sociedad plural con distintas tradiciones y aspiraciones.

La decisión, según Schmitt, prevalece sobre la discusión, si ésta se entiende como la deliberación racional y la argumentación, entonces, la dictadura implica el fin de la discusión. Esto se debe a que los estados de excepción no pueden ser resueltos por medio de la legalidad o por una deliberación racional, sino por una decisión de la autoridad (o la voluntad del dictador), es decir, el Estado es la única entidad decisiva. Por ello se verá como enemigo del Leviatán o de la soberanía del Estado ${ }^{21}$ el ámbito de lo privado cuando de éste surgen reivindicaciones individuales propias de la cultura liberal con las que se puede poner en peligro la obediencia incondicional. Así, en los momentos conflictivos entre normas se toman decisiones políticas y no en base a una ley, y, la decisión de la autoridad determina qué es una norma y qué es lo normativamente correcto.

\section{Theodor Viehweg y la tópica jurídica}

Viehweg desarrolla su noción ${ }^{22}$ de la interpretación-argumentación en su obra Tópica y jurisprudencia del año 1953, en ella su interés principal es reflexionar acerca de cómo otras formas de razonamientos con otras estructuras, como el pensamiento tópico y retórico, pueden sustentar la teoría y la práctica jurídica (en contraposición con el pensamiento sistemático o a los excesos de la visión formalista) ${ }^{23}$.

Para Viehweg el objetivo del derecho, la práctica misma del derecho se trata simplemente de la cuestión de qué sea lo justo aquí y ahora ${ }^{24}$, es decir, la búsqueda de la mejor decisión para el problema concreto que se presenta. En este sentido, el modelo de Viehweg consiste en atribuir a la praxis jurídica un carácter tópico, por ello, el intercambio de argumentos entre las partes litigantes se constituye de lugares comunes o tópicos que condensan el saber y las opiniones que en derecho rigen en un lugar y una época determinados y que han influido y permanecen en el consenso general o entre los especialistas; por ejemplo: en un alegato judicial, ganará la argumentación quien más y mejores tópicos (opiniones asumidas, decisiones tomadas, etcétera) haya sabido manejar y haya convencido o persuadido de la mejor manera.

Así, en esta forma de argumentar de Viehweg, los tópicos asumidos generalizadamente son el camino fundador de la decisión jurídica, con ello se pretendió ser un contrapunto o complemento de las corrientes sistematizadoras del derecho sustentadas y desarrolladas

\footnotetext{
${ }^{21}$ Schmitt reconstruye y asume como responsable del desarrollo histórico negativo del Leviatán las reflexiones de los pensadores judíos, a quienes se les responsabilizará de la "muerte" del Leviatán, de ahí la lamentable presencia de ideología xenófoba antisemita. Ibidem, pp. 29-30.

${ }^{22}$ Es común considerar que la propuesta de Viehweg no alcanza a ser una teoría debido a su carácter asistemático, no obstante, su gran mérito es abrir un amplio panorama para la investigación jurídica.

${ }^{23}$ Viehweg está convencido que la tópica ha prestado grandes servicios a la jurisprudencia, sin embargo una jurisprudencia fundamentada en la tópica no es un método, sino un estilo, razón por la cual tiene mucho de arbitrio amorfo y muy poco de comprobabilidad rigurosa. VIeHwEG, Theodor (2007), Tópica y Jurisprudencia, España, Thomson/Civitas, p. 123.

${ }^{24}$ Ibidem, p. 151.
} 
solamente en una lógica jurídica ${ }^{25}$ (deductiva-axiomática) de las normas. A continuación veremos las directrices del planteamiento de Viehweg.

Como es sabido, en sus tratados de lógica, Aristóteles ${ }^{26}$ realizó una distinción de los diferentes tipos de silogismos. 1) Un razonamiento demostrativo o analítico se origina de proposiciones primitivas o verdaderas (las que tienen la certidumbre en sí mismas y son propias de la filosofía); en tanto que 2) el silogismo dialéctico se construye o saca su conclusión a partir de premisas plausibles, opinables o simplemente probables, que pertenecen al campo del arte de la disputa o tópica (aquí se da una práctica intersubjetiva o intercambio dialógico ${ }^{27}$ en la que se intercambian argumentos: alguien que ofrece una tesis y alguien que la refuta); por su parte 3) el razonamiento erístico o contencioso es un caso especial que se apoya en premisas que se estiman como aparentes o probables, y que sin embargo no lo son pues se actúa de mala fe, por lo cual dicho silogismo sólo lo es en apariencia; y, finalmente, 4) existen pseudoconclusiones o paralogismos que se forman con base en proposiciones especiales de determinadas ciencias.

De igual forma, el estagirita conceptualizó los tópicos (o la tópica: doctrina del razonamiento sobre lo probable) en relación con la dialéctica y la retórica, en este sentido, si los silogismos dialéctico y retórico parten de premisas probables, la tópica o los tópicos (topoi-lugares comunes, loci comunes para los romanos) es el camino que permite descubrir los puntos de vista apropiados, los lugares comunes eficaces para discurrir de forma dialéctica sobre un tema cuya solución no rebasa el campo de lo probable.

La dialéctica aristotélica no se contrapone a la lógica, pues la diferencia entre ambas, como vimos, es la calidad epistemológica de las premisas, pues tanto las apodícticas como las dialécticas son formalmente correctas. Por otra parte, la dialéctica comparte con la retórica el tipo de premisas en que se apoyan, lo que las diferencia es el fin práctico que persiguen: la dialéctica sólo pretende demostrar la corrección o no de una conclusión a partir de premisas probables, en tanto que la retórica va más allá al querer persuadir o convencer a un auditorio de que la conclusión a la que se ha llegado es la correcta.

Para Aristóteles la dimensión lógica de la retórica tiene su base en el entimema o silogismo retórico (el cual contiene alguna proposición elíptica), éste, como no parte de principios evidentes, además utiliza otras formas de argumentar para convencer al auditorio, tales como son los endoxa (creencias antiguas, comunes e influyentes, aceptadas por los sabios y los rétores; Platón utilizó el término doxa para referirse a opiniones no fundadas).

Así pues, la tópica se encarga de la búsqueda de los lugares comunes (topoi) desde los cuales puede ser conocida una realidad, se puede fundamentar un argumento o también rebatir conclusiones o tesis. La tópica sustentada en la dialéctica y la retórica cayó en desuso a partir del siglo XVIII debido al racionalismo predominante del pensamiento ilus-

\footnotetext{
${ }^{25}$ Con respecto a la lógica jurídica, se está de acuerdo con Perelman en que ésta no existe en el sentido propio del término. Tenemos la lógica entendida como las diferentes formas de argumentar e inferir (como la lógica formal) y lo que llamamos lógica jurídica es una forma de como entendemos el derecho y lo adaptamos a la lógica, de tal manera que los razonamientos habituales de un jurista pueden seguir distintos caminos lógicos.

${ }^{26}$ Aristóteles (1987), Tratados de lógica (El organon), 8a. ed., México, Editorial Porrúa, p. 223.

${ }^{27}$ Hay que recordar que ya en la cultura medieval una actitud intelectual muy difundida, no sólo en el ámbito del derecho, era la disputatio, discusión o alegación de diversas opiniones para llegar a la verdad.
} 
trado. Esta actitud se acentuará hasta mediados del siglo xx con las doctrinas positivistas; posteriormente con las crisis mundiales, principalmente de la guerra y el genocidio nazi, se generó incertidumbre ante el progreso científico y técnico apoyado en la racionalización lógico-matemática.

En este contexto, en el campo del derecho surgirán propuestas como la de Viehweg que tratará de hacer resurgir el pensamiento tópico y retórico y su posible aplicación tanto en la teoría como en la práctica jurídica (claro está que habrá diferencias de sus planteamientos con los de Aristóteles).

Otra directriz del pensamiento de Viehweg, junto con la lógica aristotélica, la encontramos en las categorías que propone el filósofo Nicolai Hartmann, las cuales fueron asimiladas por Viehweg ${ }^{28}$. Hartmann, en sus reflexiones sobre la investigación científica, hace la distinción entre pensamiento sistemático-axiomático (Systemdenken) y pensamiento problemático (Problemdenken). El pensamiento problemático o aporético ${ }^{29}$ (que también pretende ser sistemático, sin caer en contradicción) no anticipa el sistema, es decir, se tiene que partir de la búsqueda de los fenómenos o los problemas, en tanto que en el pensamiento sistemático, los sistemas constructivos ponían como fundamento un esquema anticipado del nexo del mundo, o sea, no lo investigaban, sino que creían conocerlo de antemano.

En este contexto, Viehweg precisa que el término aporía designa precisamente una cuestión que es acuciante e ineludible, la "falta de un camino", la situación de un problema que no es posible apartar ${ }^{30}$; asimismo, la tópica jurídica es una técnica del pensamiento aporético que pretende suministrar datos para saber cómo hay que comportarse en una situación aporética, a fin de no quedar detenido sin remisión. Por esto es que la tópica se preocupa más bien por el problema concreto y desde ahí comienza a tener una visión del sistema ${ }^{31}$. Viehweg tiene una inclinación decidida por esta forma de pensamiento desprovisto de sistematicidad (la cual en su parecer es semejante a la tarea de los jurisconsultos romanos), pues cada caso concreto tiene en sí mismo diversas formas (tópicos) de ser interpretado en su contexto, en lo justo aqui y ahora a partir de la relación de elementos como la razón, la práctica y la justicia.

Específicamente, el proceder de Viehweg puede verse de esta manera: la tópica es una meditación prelógica, pues, como tarea, la inventio es primaria y la conclussio secundaria. La tópica señala cómo se encuentran las premisas; la lógica las recibe y trabaja con $e^{e l l a s^{32}}$. Así pues, la conceptualización de Viehweg sobre la estructura tópica que conviene a la jurisprudencia se caracteriza por 1) partir de la noción de pensamiento problemático (del caso concreto en litigio); 2) operar sobre la búsqueda de los topoi o lugares comunes (conceptos, proposiciones, etcétera) y, particularmente, 3 ) hacer un análisis sobre las premisas (o tópicos) de los silogismos de la argumentación antes que sobre la conclusión a la que se llega. Así pues, la tópica de Viehweg se caracteriza principalmente por su

\footnotetext{
${ }^{28}$ VIEHWEG, Theodor (2007), op. cit., nota 23, p. 57.

${ }^{29}$ Viehweg rastrea esta idea hasta Vico para rescatar-aclarar la clasificación que éste hace de los métodos científicos, calificando al antiguo método como retórico (o tópico, el cual es una herencia de la Antigüedad transmitida sobre todo por Cicerón) y al nuevo como crítico (es lo que usualmente se denomina como cartesianismo y que influirá la época de la Ilustración).

${ }^{30}$ VieHweg (2007), Ibidem, p. 56.

${ }^{31}$ Ibidem, p. 55.

${ }^{32}$ Ibidem, p. 68.
} 
oposición a los planteamientos sistemáticos. Él entiende por sistema el método deductivo axiomático en el que todas las reglas jurídicas deberían derivarse de manera necesaria de los axiomas iniciales ${ }^{33}$.

Para llevar a cabo su tarea, Viehweg propone la recuperación del concepto de tópicos, o lugares comunes, cuyo repertorio es elástico ya que puede agrandarse o empequeñecerse. Esto implica nuevos puntos de vista, es decir, nuevas interpretaciones; razón por la cual, se puede sostener, dice Viehweg, que sin interpretación no hay jurisprudencia. Así pues, Viehweg resalta que la interpretación constituye una pieza de la tópica extraordinariamente apropiada en los mencionados cambios de situación ${ }^{34}$. En este mismo contexto, el debate, según Viehweg, es la única instancia de control, pues la discusión de problemas se mantiene dentro de la dialéctica, por lo que en el marco de lo opinable se puede aspirar también a una efectiva inteligencia y no a una simple y arbitraria opinión ${ }^{35}$.

\section{Chaïm Perelman y la nueva retórica}

Gadamer, en Verdad y método (1960), hizo una referencia explícita a la importancia de la retórica en la época actual, la cual encontró un eco positivo en distintas partes, tal como puede verse en la influencia que tuvieron los trabajos de Chaïm Perelman, principalmente, en su obra magna Tratado de la argumentación. La nueva retórica (1958), en el cual se toma la praxis jurídica como punto de partida. Ahora bien, insistir en este tema no significa olvidar la relevancia de la ciencia moderna y de su aplicación a la civilización técnica actual. En esto coinciden tanto Gadamer como Perelman y ambos tratarán de explorar y ampliar el panorama de la argumentación jurídica hacia otros horizontes.

Por su parte, Perelman, después de realizar estudios sobre la lógica de Gottlob Frege, regresa a y rehabilita, igual que Viehweg (quien había dado origen a la Escuela de Maguncia en Alemania y de la cual era seguidor Perelman), los estudios de la lógica clásica de Aristóteles, Cicerón y Quintiliano. Como resultado de su búsqueda, Perelman tratará de mostrar cómo, además de la comprobación empírica y la deducción lógica, hay otras posibilidades para la argumentación y la fundamentación racional, pues no todos los razonamientos parten de premisas ciertas o axiomas, sino que hay razonamientos que tienen como punto de partida lo plausible, tal como suele ocurrir en el ámbito del derecho.

Perelman reconoce los impulsos brillantes que han desarrollado la lógica formal como un medio de demostración y su propuesta, más que sustituir la lógica, pretende complementarla, pues resulta que su campo [el de la lógica formal] está limitado... Los lógicos deben completar con una teoría de la argumentación la teoría de la demostración así obtenida. Nosotros procuraremos construirla analizando los medios de prueba de los que se sirven las ciencias humanas, el derecho y la filosofía ${ }^{36}$.

Como puede verse, Perelman enfatiza dos momentos que contrastará en su propuesta argumentativa: 1) la concepción clásica de la demostración derivada de la lógica formal y 2) la nueva forma de argumentación que él tratará de construir o razonar con sus propios

\footnotetext{
${ }^{33}$ Ibidem, p. 74.

${ }^{34}$ Ibidem, p. 71.

${ }^{35}$ Ibidem, pp. 72-73.

${ }^{36}$ Perelman, Chaïm y Olbrechts-Tyteca, Lucie (1989), Tratado de la argumentación. La nueva retórica, España, Gredos, p. 42.
} 
medios: la nueva retórica o la rehabilitación de la retórica clásica greco-romana.

Es sabido que para demostrar una proposición-conclusión se puede utilizar un método-instrumento en la que la conclusión es la expresión-resultado de una serie deductiva a partir de elementos axiomáticos. Pero, se pregunta Perelman: ¿De dónde vienen estos elementos? ¿Acaso son verdades impersonales, pensamientos divinos, resultados de experiencias o postulados propios del autor? Estas preguntas son extrañas o de poco interés para el lógico formal, no obstante cuando se trata de argumentar o de influir, por medio del discurso, en la intensidad de la adhesión de un auditorio a ciertas tesis, ya no es posible ignorar por completo, al creerlas irrelevantes, las condiciones psíquicas y sociales sin las cuales la argumentación no tendría objeto ni efecto ${ }^{37}$, ya que, toda argumentación pretende la adhesión de los individuos, la cual se logra por medio de un proceso de convencimiento intelectual o de deliberación, tendrá que haber, dice Perelman, un contacto intelectual.

Para que haya contacto intelectual se necesita la formación de una comunidad efectiva de personas, a su vez, ésta precisa una serie de condiciones. Así, para la argumentación efectiva, es indispensable la existencia de un lenguaje común, de una técnica que posibilite la comunicación. No obstante, para Perelman, eso no basta, se requiere además la contextualización o la comprensión de precondiciones de la vida en sociedad: En nuestro mundo jerarquizado, ordenado, existen generalmente reglas que establecen cómo se puede entablar la conversación, un acuerdo previo que procede de las mismas normas de la vida social ${ }^{38}$.

Es decir, para argumentar se precisa el consentimiento del interlocutor, la puesta en juego (saber escuchar-se, saber escuchar las palabras) de quienes participan en la comunicación; Gadamer conceptualizará esto con la interpretación y la fusión de horizontes. En este sentido, según Perelman, el contacto que se produce entre el orador y el auditorio no se refiere únicamente a las condiciones previas a la argumentación: también es esencial para todo su desarrollo ${ }^{39}$. Pues, la argumentación pretende obtener la adhesión de aquellos a quienes se dirige, al auditorio al que se trata de influir o al conjunto de aquellos en quienes el orador quiere influir con su argumentación ${ }^{40} ; \mathrm{y}$, para que se dé una argumentación efectiva, se tiene que considerar-conocer al auditorio lo más cercano a la realidad posible.

En este sentido, la lógica formal (que no atiende a los contenidos del pensamiento sino sólo a la validez de la estructura o de la deducción) no es suficiente, pues para argumentar y para lograr la adhesión de un auditorio es preciso considerar las condiciones sociológicas o funciones sociales desempeñadas por los oyentes, ya que son útiles para el orador porque precisan particularidades y, más aún, esto predispone la infinidad de medios para influir en tal auditorio.

Ante la variedad de auditorios, Perelman considera necesaria una técnica argumentativa capaz de imponerse en la búsqueda de la objetividad o el deseo de transcender las particularidades históricas o locales, de forma que todos acepten las tesis defendidas. A partir de esto, y teniendo en cuenta un poco los diferentes tipos de juicios que había propuesto Emmanuel Kant, Perelman elaborará la distinción entre persuadir y convencer.

\footnotetext{
${ }^{37}$ Ibidem, p. 48.

${ }^{38}$ Ibidem, p. 50.

${ }^{39}$ Ibidem, p. 54.

${ }^{40}$ Ibidem, p. 55.
} 
Nos proponemos llamar persuasiva a la argumentación que sólo pretende servir para un auditorio particular, y nominar convincente a la que se supone que obtiene la adhesión de todo ente de razón ${ }^{41}$.

Es decir, a la audiencia específica se la puede persuadir (con la acción) para que adopte-acepte un cierto punto de vista u opinión o juicio sin fundamento; $y$, por otra parte, ante una audiencia universal a la que se trata de convencer (con la inteligencia) se utilizan fundamentos, generalizaciones, principios o argumentos que todos, en términos racionales, estén dispuestos a aceptar.

Esta propuesta ontológica de Perelman puede bien llevarse al ámbito de la jurisprudencia, pues, cuando un juez emite una sentencia, se dirige específicamente a los juristas a los cuales quiere convencer con sus consideraciones. Así, el juez debe elaborar argumentos que convenzan racionalmente a un mayor número de oyentes. Esto, aunado a la preocupación del juez por la aceptación social de su decisión, evidencian que en derecho es insuficiente el razonamiento puramente formal, pues éste controla la corrección de las inferencias, pero no formula juicios sobre el valor de la conclusión.

\section{Aportaciones de la hermenéutica filosófica de Gadamer a la hermenéutica jurídica}

Con respecto a su reflexión sobre la interpretación jurídica, el punto de partida de Gadamer es que es algo obvio y natural el tránsito a la forma escrita de la norma jurídica y la constante invocación del texto como algo. Por eso, la formulación de leyes, de contratos o de decisiones legales debe ser especialmente rigurosa, y tanto más su fijación escrita. Esto permitirá que el sentido jurídico se desprenda claramente del texto y se evite el peligro de abuso o tergiversación y se pueda realizar una interpretación auténtica, aunque los autores-legisladores no estén accesibles.

Por otra parte, el razonamiento deductivo puramente formal sólo nos provee de la corrección o de la validez de nuestro silogismo. No obstante, el razonamiento jurídico va más allá de la validez, ya que se pretende encontrar una decisión justa a partir de una conclusión, y esto no es, por decirlo así, de forma impersonal; esto implicará que, en derecho, quien toma una decisión -legislador, magistrado, juez, etc.- debe asumir su responsabilidad $^{42}$; consciente de esto, el juez buscará justificar o complementar su decisión dentro de un orden jurídico en el que los precedentes legislativos sean fundamentales. Así, en el ámbito jurídico la necesidad de repensar hasta qué punto la redacción de un texto, su validez y sus precedentes o historicidad hacen referencia a la complementación de una interpretación, es decir, son parte de y posibilitan una aplicación correcta y razonable.

Zaccaria ${ }^{43}$ dice que es fácil constatar cómo en la realidad efectiva de la praxis jurídica, o sea en el momento de la interpretación y de la aplicación del derecho, se parte de los precedentes ${ }^{44}$ [de la tradición - para Gadamer-], y de ellos se aleja sólo si subsisten

\footnotetext{
${ }^{41}$ Ibidem, p. 54.

${ }^{42}$ Perelman dice que el juez no puede conformarse con motivar una decisión de manera aceptable, además debe apreciar-valorar si su decisión es justa o al menos razonable. Perelman, Chaïm (1988), La lógica jurídica y la nueva retórica, España, Civitas, pp. 93 y ss.

${ }^{43}$ ZACCARIA, Giuseppe (2010), "La jurisprudencia como fuente de Derecho: una perspectiva hermenéutica", Isonomía, No. 32, abril 2010, p. 97.

${ }^{44}$ Dworkin ha desarrollado argumentos contra el positivismo legal, uno de ellos es cuando afirma que los
} 
buenas razones para hacerlo. Y señala que es imprescindible no omitir esta característica del derecho (esta regla no escrita) para una metodología del derecho que pretenda comprender correctamente de qué modo funciona la interpretación judicial de la ley. Como ejemplo, menciona que el juez penal aprovecha el espacio hermenéutico, pues la aplicación judicial está influenciada por el contexto institucional y normativo, la comprensión de la norma, incluso los pre-juicios ${ }^{45}$, reconducibles a la categoría -si queremos polivalente-de la pre-comprensión ${ }^{46}$.

El texto jurídico no es válido hasta que se promulga; una ley encuentra su validez jurídica en su proclamación, en el haber sido dicha gana su existencia jurídica, y si no se la dice, no. Los enunciados jurídicos constatan de un modo palmario lo que es válido en el sentido jurídico del término. Es decir, los distintos niveles textuales y el carácter literario en que se va desarrollando la tradición jurídica confirman o dicen lo que es válido y sólo pueden comprenderse si se tiene en cuenta el scopus (la finalidad y la intención del texto en su integridad) de esta pretensión de validez. Pues que una constitución, las leyes, los códigos legales, los decretos, las sentencias, estén fijados por escrito es evidentemente la consecuencia de que tienen que ser válidos de forma invariable y para todos.

No obstante, el problema hermenéutico en la interpretación en general y particularmente de las órdenes es que éstas deben cumplirse conforme a su sentido (y no al pie de la letra). Esto es así debido a que un texto no es un objeto dado, sino una fase en la realización de un proceso de entendimiento ${ }^{47}$. Esto mismo ocurre en el ámbito de la hermenéutica jurídica, donde la búsqueda del juicio justo no es una mera subsunción del caso particular en algo general (las cláusulas de la ley), sino que la búsqueda de las cláusulas rectas se basa en una decisión propia creativa, complementaria o perfeccionadora del derecho ${ }^{48}$.

Por ello, para Gadamer, la idea de objetividad es lo contrario de la parcialidad o el abuso del derecho para fines particulares: La apelación a la naturaleza de la cosa invoca un orden sustraido al arbitrio humano e intenta hacer prevalecer el espiritu vivo de la justicia incluso contra la letra de la ley. La naturaleza de la cosa es, pues, también aquí algo que se hace valer, algo que debe respetarse ${ }^{49}$; es decir, la naturaleza de la cosa invoca jurídicamente un límite a la libertad humana, algo que debe respetarse.

jueces sienten la obligación de dar lo que denominó "fuerza de gravedad" a decisiones anteriores y que esta obligación contradice la doctrina positivista de la discreción judicial. Dworkin, Ronald (2008), El imperio de la justicia. De la teoría general del derecho, de las decisiones e interpretaciones de los jueces y de la integridad política y legal como clave de la teoría y práctica, Barcelona, España, Gedisa, p. 12.

${ }^{45} \mathrm{Se}$ insiste en que en este contexto los prejuicios son una especie de pre-conceptos, pre-comprensiones que llevamos a la interpretación. Esta consideración determina un círculo hermenéutico: lo que obtenemos a partir de lo que ya antes teníamos, previamente a la interpretación. Sin embargo, el círculo se rompe porque siempre hay una nueva interpretación, un descubrimiento en la comprensión del significado.

${ }^{46}$ ZACCARIA, Giuseppe (2010), art. cit., nota 43, p. 102.

${ }^{47}$ Entre las interpretaciones posibles, la escogida lo será en mérito a una actitud psicológica valorativa del intérprete. Pero lo cierto es que cuando el intérprete se siente severamente ligado al tenor literal de la ley, por parecerle ésta acaso claro indubitablemente, las motivaciones que seguramente actúan en la tarea concreta de interpretación son ciertas leyes psicológicas relativas a las asociaciones verbales. VERnENGo, Roberto J. (1994), op. cit., nota 6, p. 109.

${ }^{48}$ GADAMER (2006a), op. cit., nota 1, p. 365.

${ }^{49}$ Ibidem, p. 72. 
En el mismo sentido, y según la postura específica de Gadamer, lo que la ley prescribe, lo que es el caso de la ley, está sólo determinado unívocamente en la cabeza de peligrosísimos formalistas ${ }^{50}$. Así, es evidente -dice Gadamer- que la pretensión de validez de la palabra no le adviene sólo de su carácter material, pues que estén fijados por escrito en su pleno sentido literal conlleva su validez de forma invariable y para todos: Lo que ahi está escrito, lo que ahí está, en tanto que no sea desaprobado, constituye manifiestamente el carácter esencial de la validez del anuncio que corresponde a tales textos ${ }^{51}$.

Por ello, la vinculación entre la generalidad de la ley y la materia concreta de un caso sometido ante los tribunales de justicia constituye -Gadamer está convencido de ello ${ }^{52}$ el momento integral de todo el arte del derecho y toda la ciencia del derecho. Esta es la razón de que Gadamer afirme contundentemente que la interpretación correcta de las leyes no es una simple teoría del arte, una especie de técnica lógica de la subsunción bajo parágrafos, sino una concreción práctica de la idea del derecho. El arte de los juristas es también cultivo del derecho ${ }^{53}$.

Así pues, Gadamer afirma que es innegable que la hermenéutica es una disciplina normativa y ejerce la función dogmática de complementación jurídica. Desempeña como tal una tarea imprescindible, porque ha de colmar el hiato entre la generalidad del derecho establecido y la concreción del caso individual ${ }^{54}$.

La hermenéutica jurídica que propone Gadamer tiene dos momentos fundamentales: a) el que inicia con la consideración de que la garantía objetiva de la interpretación jurídica parte necesariamente de la forma escrita y la constante invocación del texto como algo obvio y natural (porque, justamente, lo fijado por escrito, lo consagrado como derecho sirve para despejar o evitar discusiones, abusos o tergiversaciones); y, b) la premisa de que toda norma establecida o constituida, necesita siempre de la interpretación para su aplicación práctica y esto significa, a la inversa, que toda aplicación práctica lleva ya implícita la interpretación. Por eso le compete siempre a la jurisprudencia, a los precedentes y a la praxis anterior una función legislativa ${ }^{55}$.

Gadamer retomó de Aristóteles la idea de la forma jurídica de la phrónesis. Esta virtud considerada por el filósofo griego puede funcionar como imagen directriz para la noción de justicia. ¿Cuál es la interpretación que Gadamer hace de esta virtud? Para él, lo justo está determinado en un sentido absoluto, pues está formulado en las leyes y contenido en las reglas, pero también lo que es justo no se determina por entero con independencia de la situación que me pide justicia; es decir, se precisa un saber (una tekhne) y un poder hacer; así, el arte del juez consiste en la aplicación de las leyes y las reglas (tekhne) a un caso concreto (praxis).

Para Gadamer, en la decisión justa, el que aplica el derecho se verá obligado seguramente a hacer concesiones respecto a la ley en sentido estricto, pero no porque no

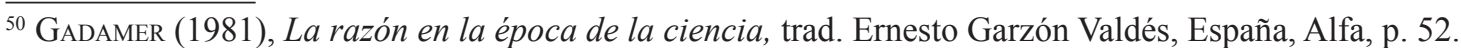

${ }^{51}$ Gadamer (1998), Arte y verdad de la palabra, pról. Gerard Vilar, trad. José Francisco Zúñiga García y Faustino Oncina, España, Paidós, pp. 26-27.

${ }^{52}$ GadAMER (1981), op. cit., nota 50, pp. 65-66.

53 Ídem.

${ }^{54}$ GADAmer (2006a), op. cit., nota 1, pp. 108-110.

${ }^{55}$ Gadamer, (2001), Antología, trad. Constantino Ruiz-Garrido y Manuel Olasagasti, España, Ediciones Sígueme, p. 206.
} 
sea posible hacer las cosas mejor, sino porque de otro modo no sería justo. Haciendo concesiones frente a la ley no elimina aspectos de la justicia, sino que, por el contrario, encuentra un derecho mejor ${ }^{56}$. Esta corrección de la ley es la idea aristotélica de epieikeia o equidad.

La epieikeia funciona como complemento, rectificación o ajuste de la ley, pues con tal idea se entiende que el problema de la interpretación comprensiva no se puede separar del problema de la aplicación ${ }^{57}$. Si bien una ley es siempre general, sin embargo, no puede implicar toda la complejidad concreta de un caso particular, por ello, una ley es insuficiente, no en razón de un defecto intrínseco, sino porque el mundo como campo de nuestras acciones es siempre imperfecto por relación al orden ideal representado por las leyes ${ }^{58}$.

Para Zaccaria ${ }^{59}$, es una característica estructural del derecho partir del caso individual, pero se debe ir más allá del caso individual para garantizar igualdad de trato, certeza de derecho, continuidad y previsibilidad de las decisiones. Además:

en la aplicación de la Constitución la regla general está representada por la razonabilidad, entendida como técnica para la satisfacción de los valores y de los principios positivizados en el texto constitucional y al mismo tiempo para gobernar los juicios de valor expresados por los poderes públicos, incluidas las Cortes judiciales. ${ }^{60}$

Gadamer está convencido de que en la búsqueda del derecho se necesita siempre la ponderación complementaria de la aequitas (equidad) y esta perspectiva de la equidad no se opone al derecho, sino que lleva a su plenitud el sentido legal mediante la atenuación de la letra. Es por ello que la interpretación del texto jurídico, como actividad creadora, no cambia en nada su pretensión de univocidad y su obligatoriedad jurídica ${ }^{61}$. Es aquí en donde podría encontrarse la tarea de la hermenéutica jurídica, complementar el aspecto técnico-metodológico con una parte histórico-jurídica.

Porque, Gadamer se pregunta: ¿se agota realmente el sentido de un texto en el sentido intencional (mens auctoris)? ¿es la comprensión una mera reproducción del producto original? Para él está claro que esto no es aplicable a la hermenéutica jurídica, que ejerce una evidente función creadora ${ }^{62}$. No obstante, se suele relegar este extremo a la esfera de las tareas normativas, considerándolo como una aplicación práctica que nada tuviera que ver

\footnotetext{
${ }^{56}$ Gadamer (2005), Verdad y método I, trad. Ana Agud Aparicio y Rafael de Agapito, 11a. ed., España, Sígueme, p. 389.

${ }^{57}$ Gadamer (2001), op. cit., nota 55, p. 73.

${ }^{58}$ Gadamer (2007), El problema de la conciencia histórica, 3a. ed., intr. y trad. Agustín Domingo Moratalla, España, Tecnos, p. 89.

${ }^{59}$ ZACCARIA, Giuseppe (2010), art. cit., nota 43. p. 100.

${ }^{60}$ Ibidem, p. 105.

${ }^{61}$ Es aventurado calificar a Gadamer como anti-metódico, asistemático o irracional, porque el insiste en que no se puede olvidar la relevancia de la ciencia moderna y de su aplicación a la civilización técnica actual y que, justamente, la tarea urgente de la hermenéutica es la de integrar la monológica de las ciencias en la conciencia comunicativa, esto quiere decir que es preciso ejercer la racionalidad a nivel práctico, social y político. GADAMER, Hans-Georg (2001), op. cit., nota 55, p. 43.

${ }^{62}$ Cfr. GADAmER, Hans-Georg (2006a), op. cit., nota 1, p. 106. Zaccaria tiene una idea muy parecida cuando dice que: En sede crítica y en perspectiva hermenéutica podemos observar que el derecho no se encuentra preconstituido ni tampoco en el "depósito" de los precedentes, pero debe ser cada vez nuevamente localizado y ejecutado a la luz de las novedades del caso individual, por lo tanto, con una relación siempre nueva y renovada entre la norma y el hecho. ZACCARIA, Giuseppe (2010), art. cit., nota 43, p. 99.
} 
con la ciencia, porque el concepto de objetividad de la ciencia exigiría atenerse al canon determinado por la mens auctoris. Pero ¿puede ser eso suficiente?

Así pues, la phrónesis entra en lo más íntimo y hondo de la hermenéutica gadameriana y, por ello, la interpretación jurídica tiene mucho que ver con la decisión moral de las opciones éticas que se nos presentan; es decir, la interpretación jurídica tiene que ver con la racionalidad-argumentación y el saber decidir ético-moral. Podemos decir que de la reflexión de Gadamer sobre la phrónesis surge el modelo de la interpretación jurídica, donde se da la jurisprudencia viviente que no separa el Derecho del hecho y la epieikeia o equidad es la habilidad para aplicar bien la ley general al caso particular.

En este contexto, Gadamer se pregunta qué es lo que mantiene cohesionada a la civilización o la cultura científica de la Edad Moderna. Su respuesta es contundente: No fue sólo cosa de la ciencia. Fue, y sigue siendo, cosa de la retórica, de esa auténtica escultora de las culturas y ese factor de su crecimiento ${ }^{63}$. Así, de manera socrática, es el arte de la retórica el que permite comunicar a otros el conocimiento de lo que es verdad y de lo que es correcto $^{64}$.

$\mathrm{Al}$ igual que ocurre en la propuesta de hermenéutica jurídica que hace Gadamer, para la retórica, lo importante no es sólo la praxis de los argumentos lógicamente concluyentes a los que tenemos que someternos sin discusión, sino también el ámbito de los argumentos convincentes o persuasivos:

determinados puntos discutibles deben llegar a dirimirse mediante una reflexión racional. El arte de hablar y argumentar (y de su otra cara silenciosa, la reflexiva deliberación consigo mismo), tienen aqui su domicilio... Cualquier praxis social -y verdaderamente también la revolucionaria-sería impensable sin la función de la retórica. ${ }^{65}$

Gadamer está convencido de que se ha hecho mala fama a la retórica cuando se la ve como una simple técnica de ornamentación del discurso ${ }^{66}$. El pensamiento científico-técnico tiene una visión unilateral de la cultura. En este sentido, la retórica trata de cómo persuadir excitando los afectos. La fuerza de convicción por medio de la palabra es la que hace falta. El hermeneuta también asegura que la tradición de la retórica, con su racionalidad de la argumentación y el uso de los afectos, es un factor definitorio de la sociedad mucho más poderoso que la sola certeza de la ciencia ${ }^{67}$. Es en este mismo sentido en el que Chaïm Perelman realizará su teoría sobre la praxis jurídica.

En nuestro intento por acercar el concepto gadameriano de retórica a la interpretación jurídica, podemos decir que el modelo básico de cualquier consenso es el diálogo y éste se rompe cuando uno de los interlocutores considera que sus tesis son superiores a las otras. Esto es aplicable a cualquier encuentro de opiniones verbales o a la comprensión de cualquier texto. Por ello, Gadamer dirá que

la hermenéutica es filosofí porque no puede limitarse a ser el arte de entender las opiniones del otro. La reflexión hermenéutica implica que en toda comprensión de

\footnotetext{
${ }^{63}$ Gadamer (2002), Acotaciones hermenéuticas, trad. Ana Agud y Rafael de Agapito, España, Trotta, p. 207.

${ }^{64}$ Ibidem, p. 74.

${ }^{65}$ Gadamer (2005), op. cit., nota 56. p. 661.

${ }^{66}$ GADAMER, Hans-Georg (2002), op. cit., nota 63, p. 208.

${ }^{67}$ Gadamer, Hans-Georg (2001), op. cit., nota 55, p. 43.
} 
algo o de alguien se produce una autocrítica. El que comprende, no adopta una posición de superioridad, sino que reconoce la necesidad de someter a examen la supuesta verdad propia. ${ }^{68}$

Sin duda, esto parece la intención de los juicios orales en México, como un nuevo tipo de sistema judicial.

Este volverse hacía el otro es el tema esencial de la retórica; y, en este proceso no hay relaciones concluyentes, pero no por eso el diálogo o la interpretación carece de sentido ni carece tampoco de fuerza convincente ni de pretensión de estar diciendo la verdad. En efecto, toda locución es tal, que lo que se quiere dar a entender se muestra desde distintos lados y se refleja, por tanto, de diversas maneras. Éste es el sentido de la conclusividad que expresa algo que tiene fuerza para convencer, sin ser una demostración terminante ${ }^{69}$.

\section{Reflexiones finales}

El juez, según Gadamer, debe referir a algo general lo particular -la norma jurídica a una situación particular. Sólo siguiendo este camino puede averiguar lo que la norma en cuestión significa en esta situación. Sin embargo, en cada uno de estos casos se trata en realidad de algo muy diferente en lo que se refiere a la aplicación de algo general a una situación particular.

Las normas jurídicas son generales en un sentido lógico y deben ser aplicadas a casos especificos de tal manera que pueda llegarse a un fallo justo. Aún cuando el juez considere que la ley es justa y adecuada no puede inferirse de las leyes el fallo en cada caso particular. Incluso, aunque no se conocía el proceso de la aplicación del derecho de manera tan aporética como lo hace Derrida, parece evidente que se trata de un proceso hermenéutico extremadamente complejo: un caso, una situación pasada, las circunstancias de un hecho electivo y este hecho mismo deben ser descritos e interpretados de tal manera que pueda aplicárseles una determinada norma jurídica.

Además. deben considerarse las circunstancias específicas del caso para que se produzca un falla que las tenga en cuenta y sea justo en este sentido. Para ello hay que interpretar la norma jurídica y eventualmente redefinida en relación con otras normas jurídicas. Y el resultado de esta operación hermenéutica compleja es la aplicación de una norma jurídica a un caso concreto.

Ante la pregunta de la interpretación jurídica de si ¿se agota realmente el sentido de un texto en el sentido de la intención del creador de la norma (la mens auctoris)? O de otra manera ¿es la comprensión una mera reproducción del producto original? Está claro para la hermenéutica jurídica de Gadamer que esto no puede ser así, dado que en el ámbito jurídico se precisa siempre y constantemente una función creadora. Así, los conceptos de la hermenéutica filosófica de Gadamer, como la comprensión, la interpretación y la aplicación, son una base para clarificar la contextualidad del trabajo del juez en la correcta interpretación de un caso particular en atención a una norma general.

\footnotetext{
${ }^{68}$ Ibidem, p. 83.

${ }^{69}$ Ibidem, p. 371.
} 


\section{Fuentes consultadas}

Aristóteles (1987), Tratados de lógica (El organon), 8a. ed. México, Editorial Porrúa.

Attili, Antonella (1997), "La sombra del Leviatán en el pensamiento de lo político de Carl Schmitt", en: Schmitt, Carl (2008), El Leviatán en la doctrina del Estado de Thomas Hobbes, México, Distribuciones Fontamara, pp. 11-34.

Bravo Regidor, Carlos, et. al., (2013), ¿Por qué leer a Schmitt hoy?, México, Distribuciones Fontamara.

CóRdova Vianello, Lorenzo (2009), "El amigo-enemigo como expresión de la antidemocraticidad del pensamiento de Carl Schmitt”, en: Bravo Regidor, Carlos, et. al., (2013), ¿Por qué leer a Schmitt hoy?, México, Distribuciones Fontamara, pp. 31-52.

Dworkin, Ronald (2008), El imperio de la justicia. De la teoría general del derecho, de las decisiones e interpretaciones de los jueces y de la integridad politica y legal como clave de la teoría y práctica, Barcelona, España, Gedisa.

GadAmer, Hans-Georg (2002), Acotaciones hermenéuticas, trad. Ana Agud y Rafael de Agapito, España, Trotta.

(2001), Antología, trad. Constantino Ruiz-Garrido y Manuel Olasagasti, España, Ediciones Sígueme.

(1998), Arte y verdad de la palabra, pról. Gerard Vilar, trad. José Francisco Zúñiga García y Faustino Oncina, España, Paidós.

(2007), El problema de la conciencia histórica, 3a. ed., intr. y trad. Agustín Domingo Moratalla, España, Tecnos.

(2010), El último dios: La lección del siglo XX. Un diálogo filosófico con Riccardo Dottori, trad. José Luis Iturrate Vea, España, Anthropos/Universidad Autónoma Metropolitana.

(1981), La razón en la época de la ciencia, trad. Ernesto Garzón Valdés, España, Alfa.

(2005), Verdad y método I, trad. Ana Agud Aparicio y Rafael de Agapito, 11a. ed., España, Sígueme.

(2006a), Verdad y método II, trad. Manuel Olasagasti, 7a. ed., España, Sígueme.

GADAMER, Hans-Georg, et al, (2006), Diccionario de Hermenéutica. Una obra interdisciplinar para las ciencias humanas, dirigida por Andrés Ortiz-Osés y Patxi Lanceros, 5a. ed., rev. y amp., España, Universidad de Deusto.

GNoli, Antonio (1995), "Entre razón y pasión. Bobbio recuerda a Schmitt", en: Schmitt, Carl (2008). El Leviatán en la doctrina del Estado de Thomas Hobbes, México, Distribuciones Fontamara, pp. 43-47.

Guastini, Riccardo (2012), Estudios sobre la interpretación jurídica, México, Porrúa/ UNAM.

Nietzsche, Friedrich (2008), La genealogía de la moral. Un escrito polémico, España, Alianza Editorial.

Perelman, Chaïm (1988), La lógica jurídica y la nueva retórica, España, Civitas.

Perelman, Chaïm y Olbrechts-Tyteca, Lucie (1989), Tratado de la argumentación. La nueva retórica, España, Gredos. 
Savigny, Friedrcih Karl von (2004), Metodología jurídica, Buenos Aires, Argentina, Valletta Ediciones.

Schmitт, Carl (2008), El Leviatán en la doctrina del Estado de Thomas Hobbes, México, Distribuciones Fontamara.

Schмiтt, Carl (2012), Posiciones ante el derecho, España, Tecnos.

Schмiтt, Carl (2009), Teología política, España, Trotta.

VIEHWEg, Theodor (2007), Tópica y Jurisprudencia, España, Thomson/Civitas.

Vernengo, Roberto J. (1994), La interpretación literal de la ley, Buenos Aires, Argentina, Abeledo-Perrot.

ZACCARIA, Giuseppe (2010), "La jurisprudencia como fuente de Derecho: una perspectiva hermenéutica”, Isonomía, No. 32, Abril 2010. 